\title{
Hand Sanitizer Ekstrak Metanol Daun Mangga Arumanis (Mangifera indica L.)
}

\author{
Dian Riana Ningsih*, Purwati Purwati, Zusfahair Zusfahair, Ahmad Nurdin \\ Jurusan Kimia Fakultas Matematika dan Ilmu Pengetahuan Alam, Universitas Jenderal Soedirman, \\ Purwokerto 53123, Indonesia. \\ *Corresponding author \\ E-mail: deeyanbik@gmail.com \\ DOI: 10.20961/alchemy.15.1.21458.10-23
}

Received 31 December 2017, Accepted 21 January 2018, Published Online 01 March 2019

\begin{abstract}
ABSTRAK
Komponen dasar yang terdapat dalam hand sanitizer yaitu senyawaan antibakteri alkohol dan triklosan. Triklosan merupakan zat antibakteri yang paling sering ditambahkan dalam hand sanitizer. Triklosan merupakan zat antibakteri yang paling sering ditambahkan dalam hand sanitizer. Namun, penggunaan triklosan dapat membuat bakteri kebal, mengganggu kerja hormon dan bersifat toksik. Senyawa aktif seperti flavonoid, alkaloid, steroid, polifenol, tanin, dan saponin pada ekstrak daun mangga arumanis (Mangifera indica L.) dapat digunakan sebagai antibakteri pengganti triklosan. Penelitian ini bertujuan untuk memformulasikan ekstrak metanol daun mangga arumanis sebagai gel hand sanitizer dan karakterisasi sediaan tersebut. Karakterisasi sediaan gel hand sanitizer meliputi uji $\mathrm{pH}$, uji daya sebar, konsistensi, homogenitas, dan uji aktivitas. Uji pH diperoleh pH dengan rentang 6,49 - 5,74. Kisaran pH tersebut telah memenuhi ketentuan SNI No. 06-2588. Karakterisasi uji daya sebar memperoleh rentang penyebaran 58,55 - 50,05 mm, dimana telah memenuhi ketentuan SNI No. 06-2588. Namun, pada konsentrasi 0 ppm pada hari ke 15 rentang penyebarannya tidak memenuhi SNI No. 06-2588. Sediaan memiliki konsistensi dalam bentuk gel yang homogen. Gel hand sanitizer ekstrak metanol daun mangga arumanis diuji aktivitasnya terhadap bakteri Staphylococcus aureus pada hari ke 0 dan 15 penyimpanan dengan zona hambat $(\phi)$ yang diperoleh sebesar 4,36 dan 10,35 mm dengan konsentrasi 5 ppm, dan 4,51 dan 12,12 mm dengan konsentrasi 10 ppm.
\end{abstract}

Kata kunci: antibakteri, daun mangga, hand sanitizer, zona hambat

\begin{abstract}
Hand Sanitizer of Methanol Extract of Manggoes Leaf (Mangifera indica L.). The main components in hand sanitizer are antibacterial compounds of alcohol and triclosan. Triclosan is the most commonly added antibacterial agent in the hand sanitizer. However, triclosan can make resistant bacteria, hormones disrupt and toxic. Mango leaf extract (Mangifera indica L.) have active compounds such as; flavonoids, alkaloids, steroids, polyphenols, tannins, and saponins that can be used as an antibacterial substitute for triclosan. This research formulates mango leaves extract for hand sanitizer followed by its characterization. The characterization includes $\mathrm{pH}$ measurement, dispersive power test, consistency, homogeneity, and activity test. The $\mathrm{pH}$ measurement obtains that the $\mathrm{pH}$ is within $6.49-5.74$. It complies with Indonesian national standard No. 06-2588 requirement. The dispersive power test found dispersion value around $58.55-50.05$ $\mathrm{mm}$, which has fulfilled the SNI No. 06-2588 provisions. However, at 0 ppm the dispersive power did not meet the SNI No. 06-2588. The formula shows a homogeneous gel. Mango leaves extract hand sanitizer gel was
\end{abstract}


tested for activity to Staphylococcus aures during 0 and 15 days of storage, the inhibition zone $(\phi)$ at 4.36 and $10.35 \mathrm{~mm}(5 \mathrm{ppm}), 4.51$ and $12.12 \mathrm{~mm}$ (10 ppm).

Keywords: antibacterial, hand sanitizer, inhibition zone, mango leaves

\section{PENDAHULUAN}

Hand sanitizer adalah suatu jenis produk kosmetika yang kerap digunakan sebagai pembersih tangan. Adanya produk hand sanitizer atau gel pembersih tangan memungkinkan masyarakat membersihkan tangan secara lebih cepat dan mudah tanpa memerlukan air. Hand sanitizer yang beredar di pasaran merupakan gel yang diberi zat aditif agen antibakteri, yang sebagian besar berupa triklosan. Selain hand sanitizer produk konsumer yang mengandung antimikroba triklosan yaitu sabun, produk perawatan pribadi, baju, cat, plastik dan mainan anak-anak (Halden, 2014). Triklosan merupakan agen antibakteri berspektrum luas yang banyak ditemukan di ekosistem akuatik, triklosan hanya sebagian hilang pada saat proses pengolahan air limbah (Dann and Hontella, 2011). Bahaya yang ditimbulkan oleh triklosan, menurut Cooney (2010) menyebutkan bahwa triklosan akan merugikan kesehatan dalam jangka panjang. Selain membuat bakteri menjadi kebal, triklosan dapat mengganggu proses normal kerja hormon dengan berubah menjadi racun tiroid, selain itu triklosan memiliki sifat toksik seperti klorofenol yang dapat menyebabkan kanker. Triklosan beracun terhadap reproduksi dan perkembangan kesehatan. Triklosan juga dapat menyebabkan iritasi kulit dan gangguan endokrin (Dann and Hontella, 2011; Schena et al., 2008). Melihat adanya dampak negatif penggunaan triklosan, maka eksplorasi potensi ekstrak tanaman sebagai agen antibakteri pengganti triklosan dalam formulasi gel hand sanitizer perlu dilakukan sebagai solusi mengatasi masalah tersebut.

Menurut Ningsih et al. (2017), ekstrak n-heksan daun sirsak dapat diformulasikan sebagai gel hand sanitizer dan telah diuji memiliki aktivitas antibakteri terhadap bakteri Propionibacterium acne. Daun binahong dapat di formulasikan menjadi hand sanitizer dan daun binahong memiliki aktivitas antibakteri terhadap E. coli (Veronita et al., 2017). Hal tersebut menggambarkan potensi ekstrak tanaman diformulasikan sebagai hand sanitizer.

Tanaman mangga arumanis (Mangifera indica L.) merupakan salah satu tanaman yang berpotensi sebagai obat. Tanaman mangga berpotensi sebagai obat herbal karena mengandung senyawa metabolit sekunder. Daun mangga arumanis mengandung senyawa metabolit sekunder seperti, flavonoid, alkaloid, steroid, polifenol, tanin, dan saponin. Ekstrak metanol daun mangga arumanis konsentrasi 1000 ppm berpotensi sebagai antijamur 
dan antibakteri yaitu mampu menghambat pertumbuhan Candida albicans dengan zona hambat sebesar 8,12 mm (Ningsih et al., 2017).

Islam et al. (2010) bahwa ekstrak etanol daun mangga memiliki aktivitas antimikroba terhadap bakteri gram positif (Staphylococcus aureus, Streptococcus agalactiae, Bacillus cereus, Bacillus megaterium, Bacillus subtilis, Lactobacillus vulgaricus) dan bakteri gram negatif (Shigella flexneri, Shigella sonei) dan fungi (Aspergillus ustus, Aspergillus niger dan Aspergillus ochraceus). Oleh karena itu pada penelitian ini akan dilakukan formulasi ekstrak daun mangga sebagai antibakteri pada gel hand sanitizer dengan menggunakan bakteri Staphylococcus aureus pada pengujian aktivitas antibakteri sediaan gel hand sanitizer. S. aureus adalah bakteri saprofit yang masuk dalam kategori bakteri gram positif. Bakteri ini termasuk dua bakteri patogen dengan tingkat penyebaran yang luas bersama bakteri E. coli. Pada saat uji aktivitas ekstrak metanol daun mangga yang telah dipekatkan diencerkan dalam aquades. Hal ini untuk meminimalisir pengaruh pelarut metanol yang digunakan pada saat ekstraksi.

\section{METODOLOGI PENELITIAN}

Peralatan yang diperlukan pada penelitian ini adalah peralatan gelas, inkubator, kompor gas, autoklaf, lemari aseptis, jarum ose, bunsen, stirer magnetik, drugal sky, crock bor, jangka sorong, $\mathrm{pH}$ meter, hot plate, spektrofotometer Genesys 20 Thermo Scientific.

Bahan yang diperlukan pada penelitian ini adalah media Nutrient Agar (NA), Nutrient Broth (NB), ekstrak metanol daun mangga arumanis, karbomer, TEA, gliserin, metil paraben, aquades, isolat bakteri $S$. aureus stok Laboratorium Mikrobiologi Fakultas Biologi UNSOED (klinis), kassa, kapas, wrapping, dan aluminium foil.

\section{Regenerasi Bakteri Uji}

Sebanyak 0,7 g media NA instan dilarutkan dalam $35 \mathrm{~mL}$ aquades pada Erlenmeyer kemudian dipanaskan di atas hot plate sampai mendidih. Kemudian dituang ke dalam 5 buah tabung reaksi masing-masing $7 \mathrm{~mL}$, lalu disterilkan dalam autoklaf pada suhu $121{ }^{\circ} \mathrm{C}$ selama 15 menit kemudian dimiringkan $30^{\circ}$ dan dibiarkan memadat. Isolat bakteri S. aureus diambil dari biakan murni yang tersedia, diambil secara aseptis dengan jarum ose dan digoreskan pada media agar miring kemudian diinkubasikan dalam inkubator pada suhu $37^{\circ} \mathrm{C}$ selama 1 x 24 jam (Ningsih et al., 2016).

Pembuatan Sediaan Hand Sanitizer (Ningsih et al., 2017)

Karbomer dikembangkan dalam aquades panas kemudian diaduk dengan stirer, ditambahkan metil paraben. Campuran ditambahkan ekstrak metanol daun mangga arumanis 
dan aquades hingga total volume $50 \mathrm{~mL}$. Jumlah ekstrak yang ditambahkan dari stok 1000 ppm diketahui melalui perhitungan $\mathrm{M}_{1} \mathrm{~V}_{1}=\mathrm{M}_{2} \mathrm{~V}_{2}$. Gliserin ditambahkan 0,5 $\mathrm{mL}$ dan TEA 0,1 mL. Formulasi gel dilakukan pengulangan sebanyak tiga kali dengan variasi konsentrasi ekstrak daun mangga arumanis berdasarkan hasil penentuan Konsentrasi Hambat Tumbuh Minimum (KHTM) yang diperoleh yaitu 1, 5, dan 10 ppm. Sediaan hand sanitizer yang telah diperoleh diuji aktivitas dan karakteristiknya dengan parameter yang sesuai ketentuan SNI No. 06-2588. Pembuatan sediaan gel hand sanitizer dilakukan berdasarkan formulasi pada Tabel 1.

Tabel 1. Formulasi sedian gel hand sanitizer

\begin{tabular}{ccccc}
\hline Bahan & F1 & F2 & F3 & F4 \\
\hline Ekstrak daun manga & $0 \mathrm{~mL}$ & $0,05 \mathrm{~mL}$ & $0,25 \mathrm{~mL}$ & $0,5 \mathrm{~mL}$ \\
Karbomer & $0,2 \mathrm{~g}$ & $0,2 \mathrm{~g}$ & $0,2 \mathrm{~g}$ & $0,2 \mathrm{~g}$ \\
TEA & $0,05 \mathrm{~mL}$ & $0,05 \mathrm{~mL}$ & $0,05 \mathrm{~mL}$ & $0,05 \mathrm{~mL}$ \\
Gliserin & $0,5 \mathrm{~mL}$ & $0,5 \mathrm{~mL}$ & $0,5 \mathrm{~mL}$ & $0,5 \mathrm{~mL}$ \\
Metil Paraben & $0,1 \mathrm{~g}$ & $0,1 \mathrm{~g}$ & $0,1 \mathrm{~g}$ & $0,1 \mathrm{~g}$ \\
Pewangi & $0,1 \mathrm{~mL}$ & $0,1 \mathrm{~mL}$ & $0,1 \mathrm{~mL}$ & $0,1 \mathrm{~mL}$ \\
Aquades & \multicolumn{4}{c}{ Ditambahkan hingga volume $50 \mathrm{~mL}$} \\
\hline
\end{tabular}

\section{Uji Karakteristik Gel}

Uji karakteristik adalah suatu pengujian yang dilakukan untuk mengetahui karakteristik sediaan yang dipengaruhi oleh variasi konsentrasi ekstrak dan waktu penyimpanan. Hal ini perlu diketahui karena dalam suatu produk memiliki suatu ketentuan layak penggunaan. Pengujian karakteristik sediaan dilakukan pada suhu kamar pada hari ke 0, 5, 10 dan 15 hari penyimpanan. Pengujian karakteristik sediaan gel meliputi pengujian homogenitas, uji daya sebar, uji pH dan uji konsistensi (Ningsih et al., 2017).

\section{Homogenitas}

Karakterisasi homogenitas bertujuan untuk mengetahui apakah sediaan yang diperoleh dalam kondisi benar-benar tercampur dari setiap bahan penyusunnya. Sediaan diambil sebanyak 0,5-1 g, kemudian diletakkan pada plat kaca dan ditindih dengan plat kaca lainnya (plat kaca dapat diganti dengan menggunakan cawan petri pada bagian alasnya atau menggunakan kaca arloji berukuran kecil). Sediaan diamati apakah tekstur sediaan homogen. Standar yang ditentukan pada homogenitas yaitu tidak adanya bulir maupun gumpalan saat sediaan ditindih plat kaca ataupun diusap pada plat kaca. 


\section{Uji pH}

Uji pH dilakukan untuk mengetahui nilai $\mathrm{pH}$ sediaan. Pada suatu produk kosmetika pasti ditentukan nilai $\mathrm{pH}$ yang dianjurkan, sesuai dengan peraturan SNI No. 06-2588 oleh karena itu perlu dilakukan uji $\mathrm{pH}$. Sebanyak 0,5 g sediaan diambil dan dilarutkan dalam 10 $\mathrm{mL}$ aquades, kemudian diukur nilai $\mathrm{pH}$-nya dengan $\mathrm{pH}$ meter. Nilai $\mathrm{pH}$ menurut standar SNI No. 06-2588 yaitu 4,5-6,5. Seluruh data pengukuran $\mathrm{pH}$ akan diolah dengan analisis variasi atau ANOVA Two Factor with Replication untuk mengetahui pengaruh penambahan ekstrak dan waktu penyimpanan terhadap nilai $\mathrm{pH}$.

\section{Uji Daya Sebar}

Uji daya sebar adalah suatu karakterisasi untuk mengetahui kemampuan sediaan dalam menyebar pada suatu permukaan. Sediaan diambil sebanyak 0,5 g, kemudian diletakkan pada plat kaca dan ditindih dengan plat kaca lainnya selama 1 menit. Diameter sediaan diukur dengan jangka sorong sebanyak 3 sisi (vertikal, horizontal dan diagonal). Sediaan ditindih kembali dengan beban 150 g selama 1 menit, kemudian diameter diukur. Nilai daya sebar sesuai standar SNI No. 06-2588 adalah 50-70 mm (Sayuti, 2015). Seluruh data dianalisis dengan ANOVA Two Factor with Replication untuk mengetahui pengaruh penambahan konsentrasi ekstrak dan lama penyimpanan terhadap nilai daya sebar.

\section{Konsistensi}

Uji konsistensi merupakan uji untuk mengetahui karakteristik sediaan terhadap pengaruh gaya sentrifugal terhadap konsistensi bentuk sediaan. Uji ini dilakukan dengan mengambil sejumlah gel dan ditempatkan pada tabung sentifus, kemudian gel disentrifugasi dengan kecepatan 3000 rpm selama 5-10 menit. Karakteristik berupa bentuk sediaan diamati apakah mengalami perubahan.

\section{Uji Aktivitas Antibakteri Sediaan Hand Sanitizer}

Uji aktivitas antibakteri dilakukan dengan cara difusi agar (sumuran). Kontrol positif yang digunakan dalam pengujian ini adalah hand sanitizer komersial, sedangkan kontrol negatif berupa sediaan tanpa penambahan ekstrak metanol daun mangga arumanis. Pengujian aktivitas antibakteri dilakukan dengan menggunakan sediaan gel berkonsentrasi ekstrak 1, 5 dan 10 ppm. Bakteri Staphylococcus aureus stok diambil satu lup ose dan diinkubasikan dalam $10 \mathrm{~mL}$ media cair NB selama 24 jam pada suhu $37{ }^{\circ} \mathrm{C}$. Biakan yang telah diinkubasi diambil dan diukur OD (optical density) pada panjang gelombang $600 \mathrm{~nm}$. Nilai OD pada biakkan ditentukan pada nilai 0,6; sehingga biakan diambil sebanyak $100 \mu \mathrm{L}$. Setelah itu biakan dituang dalam media NA dalam cawan petri. Bakteri disebar dengan teknik spread plate dengan menggunakan drugal sky. Media agar yang telah berisi biakan 
bakteri dilubangi dengan diameter $(\phi) \pm 6 \mathrm{~mm}$ mengunakan crock bor. Sediaan gel yang akan diujikan dimasukkan dalam lubang hingga lubang terisi penuh sediaan gel. Setelah itu media agar diinkubasi selama 24 jam pada suhu $37{ }^{\circ} \mathrm{C}$. Aktivitas antibakteri ditinjau dari adanya zona hambat di sekitar lubang, zona hambat diukur diameternya menggunakan jangka sorong (Ningsih et al., 2017).

\section{HASIL DAN PEMBAHASAN}

\section{Pembuatan Sediaan Gel Hand Sanitizer}

Sediaan gel hand sanitizer dibuat dengan cara formulasi terhadap ekstrak daun mangga arumanis dalam sediaan agar potensinya termanfaatkan secara optimal. Adanya potensi sebagai antibakteri pada ekstrak metanol daun mangga arumanis maka sediaan gel hand sanitizer dapat menjadi salah satu solusi yang cocok dilakukan.

Pembuatan sediaan gel pada penelitian ini dilakukan dengan mengembangkan gelling agent berupa karbomer dalam aquades kemudian diaduk dengan magnetic stirrer. Karbomer dikembangkan pada aquades dengan volume setengah dari volume total sediaan. Pengadukan perlu dilakukan untuk mempermudah karbomer larut dalam aquades. Proses pengadukan dilakukan dengan kecepatan sedang karena keperluan pengadukan hanya untuk menghomogenkan saja. Bila dilakukan dengan kecepatan tinggi maka warna gel akan berkabut dan tidak jernih, sedangkan bila terlalu pelan maka akan menimbulkan terbentuknya aglomerat. Aglomerat merupakan gumpalan-gumpalan yang dalam hal ini adalah karbomer yang tidak terlarut secara sempurna. Aquades bersama ekstrak ditambahkan kembali setelah karbomer mulai mengembang. Pengadukan diakhiri setelah 2 menit ketika semua komponen pendukung telah ditambahkan. Komponen pendukung yang diperlukan pada formulasi sediaan ini meliputi trietanolamin, metil paraben, gilserin, pewangi aroma mangga serta ekstrak metanol daun mangga arumanis.

Formulasi sediaan gel dikatakan baik ketika semua bahan telah terdistribusi secara merata tanpa adanya gumpalan-gumpalan pada sediaan dan memiliki warna yang nampak bening. Komponen pendukung dapat ditambahkan ketika karbomer telah dikembangkan secara sempurna, ditandai dengan tidak adanya gumpalan karbomer pada sediaan. Komponen pendukung yang ditambahkan pertama adalah metil paraben.

Metil paraben atau nipagin merupakan salah satu komponen yang ditambahkan dalam sediaan, metil paraben berperan sebagai pengawet. Pengawet ditambahkan bertujuan untuk mencegah kerusakan pada sediaan gel. Kerusakan yang dimaksud adalah seperti munculnya bintik hitam pada sediaan, munculnya mikroba seperti jamur dan bakteri, warna 
yang semakin keruh serta bau yang tidak sedap. Konsentrasi nipagin dalam sediaan perlu diuji hingga tidak dapat memberikan aktivitas penghambatan terhadap bakteri S. aureus berupa zona hambat. Penggunaan nipagin setelah pengujian adalah sebesar 0,01 g dengan referensi penggunaan sebelumnya sebesar $0,1 \mathrm{~g}$. Hal ini perlu dilakukan agar kemampuan penghambatan ekstrak metanol daun mangga terhadap bakteri $S$. aureus dapat berjalan secara optimal dan teramati secara baik. Metil paraben tidak membutuhkan waktu yang lama untuk bercampur dalam sediaan, setelah itu gliserin dapat ditambahkan kedalam sediaan (Abdassah et al., 2014).

Gliserin dalam formulasi sediaan gel hand sanitizer berperan sebagai pelembab yang berguna untuk menghindari rasa kering pada kulit saat pemakaian (Shu, 2013). Gliserin sebagai pelembab dapat berperan juga dalam memodifikasi sifat pembawa serta kondisi kulit itu sendiri untuk meningkatkan kemampuan penetrasi sediaan pada kulit. Meningkatnya kemampuan penetrasi menjadikan molekul senyawa aktif dari ekstrak metanol daun mangga arumanis dapat berdifusi pasif secara optimal (Anwar, 2012). Proses penambahan gliserin perlu diamati secara seksama untuk memastikan seluruh gliserin tercampur dalam sediaan. Pencampuran komponen pendukung dipermudah dengan adanya penambahan trietanolamin (TEA).

TEA secara umum berperan sebagai emulsifier, surfaktan dan emulgator. TEA kerap digunakan dalam produk kosmetik ataupun produk sediaan topikal. TEA dalam formulasi sediaan gel hand sanitizer berfungsi sebagai emulgator. Emulgator adalah bahan aktif permukaan yang dapat menurunkan tegangan permukaan, sehingga dapat mencegah adanya distribusi bahan pendukung yang tidak merata seperti gliserin yang memiliki viskositas tinggi. Selain sebagai emulgator, TEA berperan juga dalam menetralkan karbomer serta meningkatkan viskositas sediaan. Penambahan TEA kedalam sediaan akan bereaksi dengan karbomer sebagai gelling agent.

Penambahan TEA dalam sediaan dengan gelling agent berupa karbomer merupakan reaksi yang menentukan dalam terbentuknya sediaan gel. Karbomer dinetralkan dengan menambahkan basa karena sifatnya yang merupakan asam lemah dengan penggunaan amina organik sebagai agen penetral, pada formulasi ini digunakan TEA sebagai basa penetral. Karbomer pada kondisi asam gugus karboksil dalam struktur molekul karbopol tidak terionisasi. Apabila $\mathrm{pH}$ dispersi karbomer dinetralkan dengan penambahan basa, maka secara progresif gugus karboksil akan terionisasi. Gugus karboksil yang terionisasi berinteraksi dengan TEA. Hasil interaksi yang terbentuk yaitu gugus karboksil menjadi bermuatan negatif $-\mathrm{COO}^{-}$yang semula $-\mathrm{COOH}$ dan TEA berubah menjadi bermuatan positif 
karena mendapat tambahan atom hidrogen yang berikatan pada atom N. Adanya gaya tolak menolak antara gugus yang terionkan menyebabkan ikatan hidrogen pada gugus karboksil meregang sehingga terjadi peningkatan viskositas. Kemampuan TEA dalam mengemulsi dalam formulasi menjadikan sediaan stabil dan dispersi yang terbentuk terasa halus (Florence and Attwood, 1998).

\section{Uji Karakteristik Sediaan}

\section{Homogenitas}

Uji homogenitas merupakan uji untuk mengetahui apakah seluruh komponen dalam sediaan telah terdistribusi secara merata. Bentuk sediaan gel yang baik menurut SNI adalah sediaan gel yang tidak terdapat bulir-bulir atau butiran kasar pada sediaan. Bulir-bulir dapat terbentuk ketika proses pengembangan karbomer tidak sempurna. Pengujian dapat dilakukan dengan cara menempatkan sediaan gel pada dua buah kaca objek. Seluruh sediaan gel dengan konsentrasi ekstrak 0, 1, 5 dan 10 ppm memiliki susunan yang homogen dan tidak terdapat butiran kasar. Selama penyimpanan 15 hari seluruh konsentrasi memiliki tingkat kestabilan yang baik, ditunjukkan dengan gel tetap homogen. Hal ini dipengaruhi oleh emulgator yang bekerja secara optimal. Berdasarkan hasil pengujian tersebut maka sediaan gel hand sanitizer yang diformulasikan telah memenuhi ketentuan SNI No 06-2588.

\section{Uji pH}

Nilai $\mathrm{pH}$ merupakan karakteristik yang perlu diperhatikan dalam suatu formulasi sediaan topikal. Uji $\mathrm{pH}$ bertujuan untuk mengetahui nilai $\mathrm{pH}$ suatu sediaan apakah dapat diterima oleh kulit. Nilai pH yang dianjurkan pada suatu sediaan topikal adalah pada rentang 4,5-6,5. Kondisi sediaan yang terlalu asam akan mengakibatkan kulit menjadi iritasi, sedangkan kondisi yang terlalu basa dapat membuat kulit menjadi bersisik (Titaley et al., 2014). Hal tersebut terjadi karena adanya kerusakan pada bagian epidermis kulit khususnya bagian stratum corneum. Uji pH dilakukan dengan melarutkan sebanyak 0,5 g sediaan gel hand sanitizer dalam $10 \mathrm{~mL}$ aquades. Perlakuan ini bertujuan untuk mempermudah pengukuran nilai $\mathrm{pH}$ pada sediaan, karena sediaan berbentuk gel semisolid. Hasil uji pH dapat dilihat pada Gambar 3. 


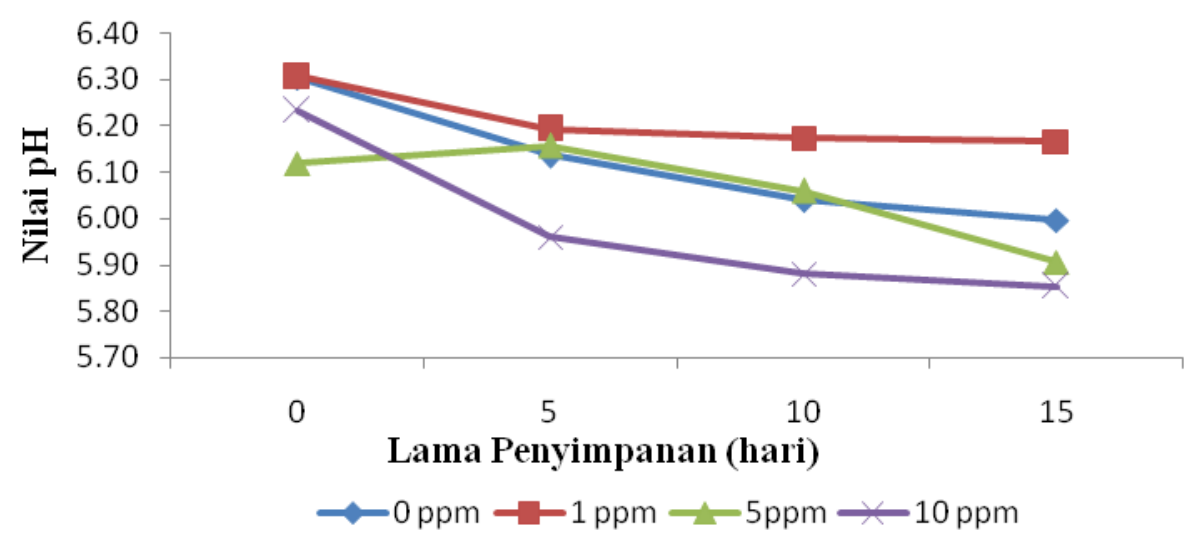

Gambar 3. Grafik hasil uji pH sediaan gel hand sanitizer

Proses pengujian $\mathrm{pH}$ dilakukan setiap 5 hari sekali selama 15 hari penyimpanan. Kecenderungan yang terjadi berdasar hasil pengujian selama 15 hari penyimpanan yaitu $\mathrm{pH}$ semakin turun, diperoleh nilai $\mathrm{pH}$ hari ke 0 lebih basa. Variasi konsentrasi ekstrak yang ditambahkan pada sediaan secara statistik tidak memberikan pengaruh secara signifikan (tidak berbeda nyata). Kecenderungan nilai $\mathrm{pH}$ terhadap konsentrasi ekstrak berbanding terbalik, konsentrasi ekstrak yang ditambahkan semakin besar maka nilai $\mathrm{pH}$ semakin turun (semakin asam). Nilai pH sediaan yang diujikan memiliki rentang yaitu 6,49-5,74.

Data hasil uji $\mathrm{pH}$ yang dipengaruhi terhadap faktor penyimpanan dianalisis statistik menggunakan ANOVA dan uji lanjut Duncan. Hasil statistik menunjukkan tidak adanya perbedaan secara signifikan nilai $\mathrm{pH}$ pada hari ke 0 dengan hari ke 5 dan 10 . Perbedaan signifikan terjadi antara nilai $\mathrm{pH}$ hari ke 0 dan hari ke 15 . Nilai $\mathrm{pH}$ tidak mengalami perbedaan secara nyata (tidak signifikan) pada penyimpanan hari ke hari (hari ke 0 ke 5 , hari 5 ke 10 dan hari ke 10 ke 15). Penurunan nilai $\mathrm{pH}$ ke arah asam yang terjadi selama penyimpanan dapat disebabkan adanya dekomposisi dari karbomer pada gugus karboksilatnya, sehingga keasaman sediaan meningkat. Nilai uji $\mathrm{pH}$ telah memenuhi ketentuan SNI No. 06-2588, yang mencantumkan nilai $\mathrm{pH}$ suatu sediaan dinyatakan baik pada nilai $\mathrm{pH}$ antara 4,5-6,5.

\section{Uji Daya Sebar}

Pengujiaan daya sebar bertujuan untuk mengetahui kemampuan sediaan gel hand sanitizer menyebar pada kulit. Penyebaran berkaitan dengan kemampuan sebaran senyawa aktif yang terkandung dalam gel pada kulit. Ekstrak metanol daun mangga arumanis (Mangifera indica L.) mengandung senyawa aktif, flavonoid, alkaloid, steroid, polifenol, tanin dan saponin (Ningsih et al., 2017). Distribusi senyawa aktif sangat perlu diperhatikan 
karena menyangkut efektivitas dan efisiensi fungsinya. Hasil uji daya sebar dapat dilihat pada Gambar 4.

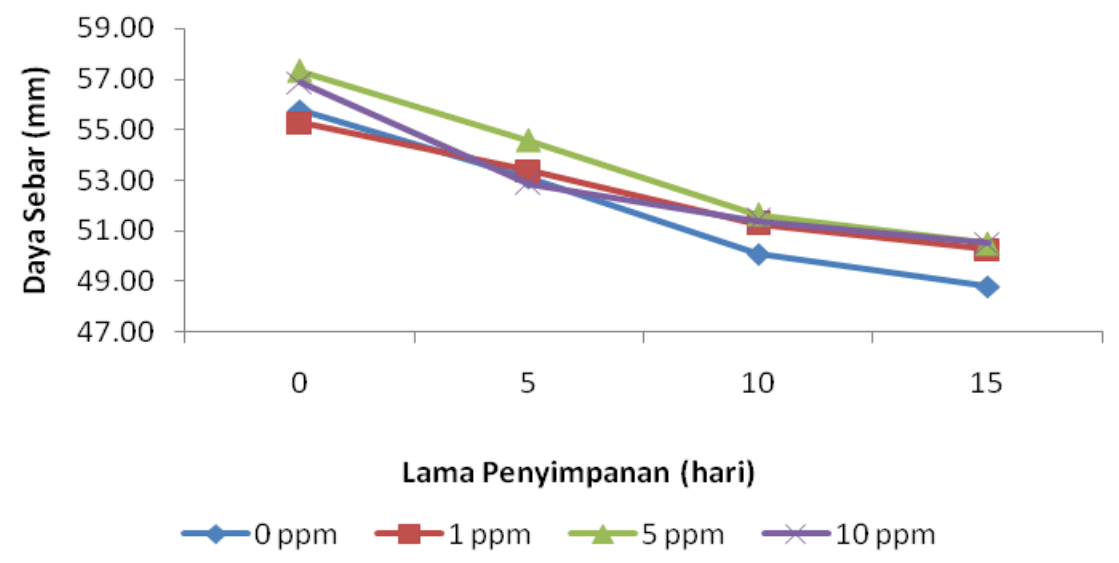

Gambar 4. Grafik uji daya sebar

Hasil uji daya sebar suatu sediaan harus mengacu pada standar SNI No. 06-2588 yang berlaku, daya sebar yang baik memiliki nilai 50-70 mm, nilai ini dianggap sebagai kondisi semisolid yang nyaman dan stabil. Hasil pengujian yang telah dilakukan diketahui bahwa terdapat sediaan yang tidak memenuhi standar SNI No. 06-2588 yaitu pada hari penyimpanan ke 15 pada konsentrasi 0 ppm, sedangkan konsentrasi lain memenuhi SNI No. 06-2588. Selama 15 hari penyimpanan nilai daya sebar yang diperoleh dengan konsentrasi 0 ppm sebesar 56,39-48,34 mm, konsentrasi 1 ppm 58,1-50,05 mm, konsentrasi 5 ppm 58,35-50,45 mm serta konsentrasi 10 ppm 58,55-50,05 mm.

Konsentrasi ekstrak metanol daun mangga arumanis yang ditambahkan secara statistik tidak memberikan pengaruh (tidak berbeda nyata) terhadap nilai daya sebar. Nilai daya sebar pada seluruh hari penyimpanan diuji secara statistik untuk mengetahui adanya pengaruh faktor lama penyimpan, hasil yang diperoleh secara statistik berbeda nyata (signifikan). Hal ini menyatakan bahwa faktor lama penyimpanan memberikan pengaruh terhadap nilai daya sebar sediaan gel. Nilai daya sebar dapat terpengaruh dengan lama penyimpanan diduga karena kontak sediaan gel dengan udara secara terus menerus. Interaksi dengan udara secara terus menerus menjadikan sediaan gel kaku dapat diketahui dari sifat karbomer sebagai gelling agent yang higroskopis. Secara keseluruhan nilai daya sebar telah memenuhi standar SNI No. 06-2588.

\section{Konsistensi}

Konsistensi merupakan karakteristik fisik yang sangat perlu diperhatikan pada sediaan semisolid seperti gel. Nilai konsistensi berkaitan dengan kemampuan penetrasi pada suatu sediaan. Uji konsistensi pada suatu sediaan dilakukan dengan menggunakan ependorf 
dan disentrifus selama 10-15 menit pada kecepatan $3000 \mathrm{rpm}$. Hasil pengujian konsistensi sediaan gel hand sanitizer untuk hari ke 0 pada semua formulasi yaitu konsistensi pada bentuk gel, tidak terdapat perubahan bentuk seperti mencair kembali. Hal tersebut menunjukan bahwa seluruh gel yang diformulasikan telah memadat secara sempurna. Hasil uji konsistensi pada hari ke 5 hingga hari ke 15 menunjukkan sediaan konsisten dalam bentuk gel.

Seluruh sediaan dengan berbagai variasi konsentrasi ekstrak 1, 5 dan 10 ppm menunjukkan konsistensi bentuk gel. Adanya faktor penyimpanan selama 15 hari sediaan tetap menunjukan konsistensi bentuk gel. Suatu sediaan gel seperti halnya handsanitizer tidak dapat mengalami proses penetralan dan mengental secara langsung. Proses penetralan dan pengentalan optimal dapat dicapai pada waktu 5 menit hingga 3 jam (Anwar, 2012). Konsistensi suatu sediaan gel dipengaruhi oleh basis pembentuk gel itu sendiri yaitu karbomer, terjadinya perbesaran ukuran karbomer dengan pelarut di dalam sediaan dapat meningkatkan konsistensi ge. Seluruh hasil pengujian memenuhi ketentuan SNI No. 062588 bahwa sediaan gel harus memiliki konsistensi bentuk yaitu semisolid.

\section{Aktivitas Antibakteri Sediaan Gel Hand sanitizer}

Uji aktivitas antibakteri sediaan gel hand sanitizer dilakukan untuk mengetahui potensi antibakteri ekstrak metanol daun mangga arumanis dalam bentuk sediaan gel. Ekstrak metanol yang digunakan merupakan ekstrak metanol pekat yang telah diencerkan menggunakan aquades kemudian diformulasikan menjadi sediaan salep. Pengujian sediaan salep dilakukan pada hari ke 0 dan 15 , hal ini bertujuan untuk mengetahui apakah sediaan tetap memiliki aktivitas antibakteri dengan mendapat perlakuan penyimpanan selama 15 hari. Seluruh sediaan gel diujikan dengan menggunakan kontrol positif berupa hand sanitizer komersial konsentrasi 10 ppm. Hasil Uji aktivitas sediaan gel hand sanitizer dapat dilihat pada Gambar 5.

Zona hambat yang diperoleh pada hari ke 0 dengan konsentrasi ekstrak 1, 5 dan 10 ppm secara berurutan $(0 ; 4,36$ dan 4,51 mm). Zona hambat pada kontrol positif sebesar 6,31 $\mathrm{mm}$ dan kontrol negatif tidak menghasilkan zona hambat. Zona hambat pada hari ke 15 dengan konsentrasi 1, 5 dan $10 \mathrm{ppm}$ secara berurutan (0;10,35 dan 12,12 mm). Zona hambat kontrol positif pada hari ke 15 yaitu $7,8 \mathrm{~mm}$ dan kontrol negatif yaitu $0 \mathrm{~mm}$ (tidak menunjukkan zona hambat). Hasil uji aktivitas yang diperoleh dari sediaan gel hand sanitizer pada konsentrasi ekstrak metanol daun mangga arumanis 5 dan 10 ppm menunjukkan bahwa ekstrak memiliki aktivitas antibakteri dalam sediaan gel hand sanitizer yang diformulasikan. Hasil uji aktivitas antibakteri yang dipengaruhi oleh faktor perlakuan penyimpanan selama 
15 hari menghasilkan zona hambat pada sediaan gel konsentrasi 5 dan 10 ppm. Hasil tersebut menunjukkan bahwa dengan adanya penyimpanan selama 15 hari sediaan masih memiliki aktivitas antibakteri. Zona hambat pada konsentrasi 5 dan $10 \mathrm{ppm}$ secara statistik tidak berbeda nyata (tidak signifikan) pada dua hari pengujian, oleh sebab itu konsentrasi sediaan gel 5 ppm dinilai lebih efektif aktivitas antibakterinya.

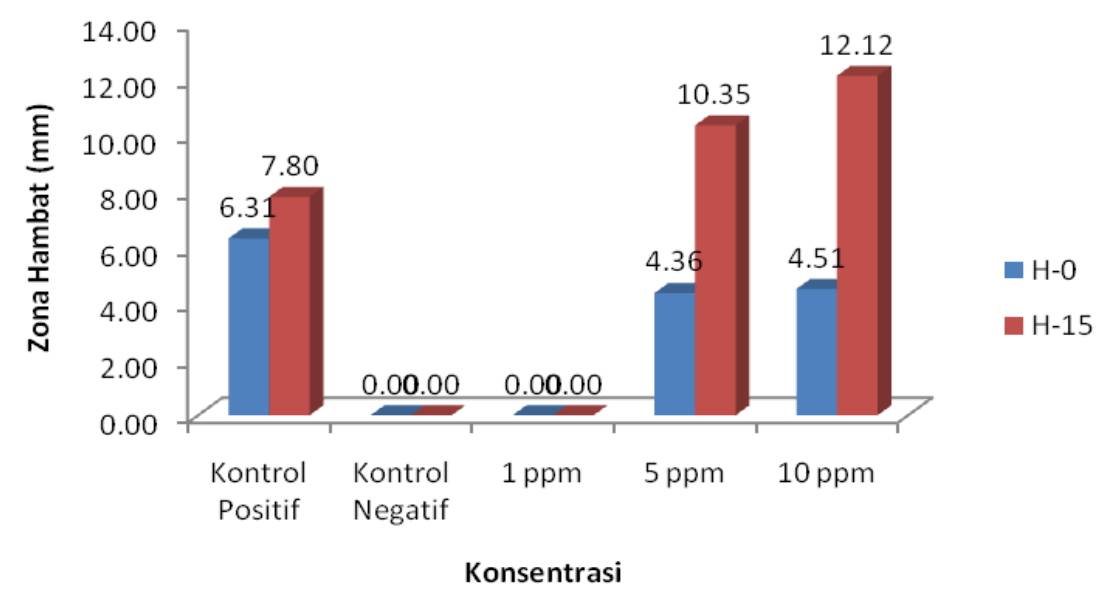

Gambar 5. Grafik hasil uji aktivitas antibakteri sediaan gel hand sanitizer terhadap bakteri S. aureus

Zona hambat yang diperoleh pada hari ke 0 dengan konsentrasi ekstrak 1, 5 dan 10 ppm secara berurutan $(0 ; 4,36$ dan 4,51 mm). Zona hambat pada kontrol positif sebesar 6,31 $\mathrm{mm}$ dan kontrol negatif tidak menghasilkan zona hambat. Zona hambat pada hari ke 15 dengan konsentrasi 1, 5 dan 10 ppm secara berurutan (0;10,35 dan 12,12 mm). Zona hambat kontrol positif pada hari ke 15 yaitu $7,8 \mathrm{~mm}$ dan kontrol negatif yaitu $0 \mathrm{~mm}$ (tidak menunjukkan zona hambat). Hasil uji aktivitas yang diperoleh dari sediaan gel hand sanitizer pada konsentrasi ekstrak metanol daun mangga arumanis 5 dan 10 ppm menunjukkan bahwa ekstrak memiliki aktivitas antibakteri dalam sediaan gel hand sanitizer yang diformulasikan. Hasil uji aktivitas antibakteri yang dipengaruhi oleh faktor perlakuan penyimpanan selama 15 hari menghasilkan zona hambat pada sediaan gel konsentrasi 5 dan 10 ppm. Hasil tersebut menunjukkan bahwa dengan adanya penyimpanan selama 15 hari sediaan masih memiliki aktivitas antibakteri. Zona hambat pada konsentrasi 5 dan $10 \mathrm{ppm}$ secara statistik tidak berbeda nyata (tidak signifikan) pada dua hari pengujian, oleh sebab itu konsentrasi sediaan gel 5 ppm dinilai lebih efektif aktivitas antibakterinya.

Kontrol positif yang digunakan pada penelitian ini adalah produk gel hand sanitizer yang beredar di pasaran. Produk gel komersial memiliki daya hambat yang tidak berbeda secara signifikan bila dibandingkan dengan zona hambat gel yang diformulasikan. Produk gel hand sanitizer komersial mengandung agen antibakteri berupa triklosan dan terdapat pula 
alkohol 60\% didalamnya. Secara umum alkohol dalam hal ini etanol memang sudah biasa dijadikan sebagai antibakteri maupun desinfektan sehingga pasti memberikan kontribusi pembentukan zona hambat pada kontrol positif. Triklosan merupakan agen antibakteri yang memang lazim ditambahkan dalam sediaan gel hand sanitizer. Menurut Shu (2013) triklosan mempunyai daya antimikroba dengan spektrum yang luas mencakup bakteri gram positif dan negatif, sehingga lazim digunakan dalam sediaan gel hand sanitizer komersial.

\section{KESIMPULAN}

Sediaan hand sanitizer memiliki konsistensi bentuk gel yang homogen. Uji $\mathrm{pH}$ diperoleh $\mathrm{pH}$ dengan rentang 6,49-5,74. Kisaran $\mathrm{pH}$ tersebut telah memenuhi ketentuan SNI No. 06-2588. Karakterisasi uji daya sebar memperoleh rentang penyebaran 58,55-50,05 mm dimana telah memenuhi memenuhi ketentuan SNI No. 06-2588. Namun pada konsentrasi 0 ppm pada hari ke 15 rentang penyebaran belum memenuhi SNI No. 06-2588. Hand sanitizer ekstrak metanol daun mangga arumanis diuji aktivitas antibakterinya terhadap bakteri $S$. aureus pada hari ke 0 dan 15 penyimpanan dengan zona hambat $(\phi)$ yang diperoleh sebesar 4,36 dan 10,35 mm dengan konsentrasi 5 ppm, 4,51 dan 12,12 mm dengan konsentrasi 10 ppm.

\section{DAFTAR PUSTAKA}

Abdassah M., Omandra, F.S., and Mita. S.R., 2014. Profil Permeasi In Vitro Gel Mata Kloramfenikol pada Membran Kornea Mata Kelinci dengan Metode Sel Difusi Franz. Journal Farmaka 13(4), 1-9.

Anwar, E., 2012. Eksipien dalam Sediaan Farmasi. Dian Rakyat. Jakarta.

Cooney, C.M., 2010. Triclosan Comes under Scrutiny. Environmental Health Perspectiveive $118(6)$, A242.

Dann, A.B., and Hontella, A., 2011. Triclosan: Enviromental Exposure, Toxicity and Mechanism of Action. Journal Applied Toxicology 31, 285-311.

Florence, A.T., and Attwood, D., 1998. Physicochemical Principles of Pharmacokinetic4th $E d$. MacMillan, London.

Halden, R.U., 2014. On the need and Speed of Regulating Triclosan and Triclocarban in The United State. Environmental Science Technology 48, 3603-3611.

Islam, M., Mannan, M., and Kabir. M., 2010. Analgesic Antiinflammatory and Antimicrobial Effects of Etanol Extract of Mango Leaves. Journal of Bangladesh 8 (2), 239-244.

Ningsih, D.R., Zusfahair, and Kartika, D., 2016. Identifikasi Senyawa Metabolit Sekunder Serta Uji Aktivitas Ekstrak Daun Sirsak Sebagai Antibakteri. Jurnal Molekul 11(1), 101-111. 
Ningsih, D.R., 2017. Ekstrak Daun Mangga (Mangifera Indica L.) Sebagai Antijamur Terhadap Jamur Candida albicans dan Identifikasi Golongan Senyawanya. Jurnal Kimia Riset 2(1), 61-68.

Ningsih, D. R, Zusfahair, D. Kartika, and A. Fatoni., 2017. Formulation of Handsanitizer with Antibacterials Substance from n-hexane Extract of Soursop Leaves (Annona Muricata Linn). Malaysian Journal of Fundamental and Applied Sciences 13(1), 15.

Sayuti, N.A., 2015. Formulasi dan Uji Stabilitas Fisik Sediaan Gel Ekstrak Daun Ketepeng Cina (Cassia alata L.). Jurnal Kefarmasian Indonesia 5(2), 10-14.

Schena D., Papagrigoraki, A., and Girolomani, G., 2008. Sensitizing Potential of Triclosan and Triclosan Based Skin Care Product in Patients with Chronic Ecsema. Dermatologic Theraphy 21, S35-SS8.

Shu, M. 2013. Formulasi Sediaan Gel Handsanitizer dengan Bahan Aktif Triklosan 0,5\% dan 1\%. Jurnal Ilmiah Mahasiswa Universitas Surabaya 2(1), 15-22.

Standar Nasional Indonesia. 1992. Deterjen Sintetik Cair Pembersih Tangan. Badan Standarisasi Nasional. No. 06-2588.

Titaley, S., Fatimawali and Lolo, W.A., 2014. Formulasi Dan Uji Efektifitas Sediaan Gel Ekstra Etanol Daun Mangrove Api-Api (Avicennia Marina) Sebagai Antiseptik Tangan. Jurnal Ilmiah Farmasi 3(2), 99-106.

Veronita, F., Wijyanti, N., and Mursiti, S., 2017. Isolasi dan Uji Aktivitas Antibakteri Daun Binahong serta Aplikasinya sebagai Hand Sanitizer. Indonesian Journal Chemical Science 6(3), 138-144. 